\title{
Mostra de Ideias: aplicação de uma metodologia gamificada e baseada em problemas no curso de Sistemas de Informação da Universidade do Estado de Mato Grosso
}

\author{
Mauro F. Santos Junior ${ }^{1}$, Sergiana Alves da Silva ${ }^{2}$ \\ ${ }^{1}$ Faculdade de Ciências Exatas e Tecnológicas (FACET) \\ ${ }^{2}$ Faculdade de Ciências Sociais Aplicadas (FACISA) \\ Universidade do Estado de Mato Grosso (UNEMAT) - Sinop - MT - Brasil \\ mauro.junior@unemat.br, sergiana.alves@unemat.br
}

\begin{abstract}
To make the teaching-learning process more motivating in the Information Systems Course, the project Mostra de Ideias was developed: a gamified and problem-based methodology. It was structured in the competition format, and the teams aimed to create startups to present the best and most viable technological solution to real problems. The competition phases included workshops with invited specialists, increasing the content of the discipline and the students' engagement. The validation of this proposal occurred through qualitative and quantitative analysis, and an increase in academic performance in the discipline was verified.
\end{abstract}

Resumo. Para tornar o processo de ensino-aprendizagem mais motivador no Curso de Sistemas de Informação, foi desenvolvido o projeto Mostra de Ideias: uma metodologia gamificada e baseada em problemas. Foi estruturada no formato de competição, e as equipes tinham como objetivo criar startups para apresentar a melhor e mais viável solução tecnológica para problemas reais. As fases da competição incluíam oficinas com especialistas convidados, incrementando o conteúdo da disciplina e o engajamento dos alunos. A validação desta proposta ocorreu através de análise qualitativa e quantitativa, e foi verificado o aumento do desempenho acadêmico na disciplina.

\section{Introdução}

Como resultado da evolução das tecnologias e das mudanças no perfil dos acadêmicos (cada vez mais as turmas são compostas por nativos digitais), é cada vez mais crítica para a Universidade a necessidade de direcionar esforços para o engajamento do aluno, principalmente através de novas metodologias. Este trabalho apresenta uma proposta de metodologia ativa para estimular os estudantes através da resolução de problemas reais usando a tecnologia como meio de transformação.

A Mostra de Ideias é uma metodologia que incorpora os conceitos de Gamificação e Aprendizagem Baseada em Problemas (da sigla em inglês PBL - Problem Based Learning) para tornar o processo de ensino-aprendizagem mais motivador. Vianna et al. (2013) esclarece que gamificação é o uso de dinâmicas e mecanismos de jogos para a motivação e engajamento na resolução de problemas. Utilizados em sala de aula, a gamificação pode motivar e engajar os alunos no desenvolvimento das atividades (Gonçalves et al., 2019). Já a PBL é uma metodologia ativa que tem como alvo principal 
a aprendizagem de uma base de conhecimento integrada e estruturada em torno de problemas reais e o desenvolvimento de habilidades de aprendizagem autônoma e de trabalho em equipe, tal como ocorre em situações práticas (Barrows, 1996).

Como trabalho correlato pode-se citar a metodologia executada em duas turmas do curso de Engenharia Civil que demonstrou ser eficaz e prazerosa para os envolvidos (Silva et al., 2015). Em Guedes et al. (2015) expõe-se a experiência de aluno e professor acerca da aplicação da PBL no curso de Administração, e em Santos et al. (2007), tem-se o relato da experiência aplicada ao curso de Engenharia de Computação expondo as dificuldades encontradas durante a jornada. Já o projeto Células Empreendedoras (Lirbório, 2019) e a iniciativa Startup Weekend (Techstars, 2020), que definem metodologias para criação de startups, são as inspirações diretas para este trabalho.

Nesta direção, foi desenvolvida a Mostra de Ideias no curso de Sistemas de Informação da Faculdade de Ciências Exatas e Tecnológicas da Universidade do Estado de Mato Grosso (UNEMAT), campus de Sinop-MT. Trata-se de uma metodologia no formato de competição cujo objetivo consistiu em transformar o ensino em uma experiência, fazendo com que os alunos aprendessem a resolver problemas relevantes de forma criativa através de modelos de negócio inovadores com base tecnológica (startups). Foi aplicado em turmas de primeiro semestre (com média de 30 alunos por turma), na disciplina de Fundamentos de Sistemas de Informação (60 horas), entre 2017-1 e 2019-2, contando seis (06) edições e cento e setenta e oito (178) participantes.

\section{Metodologia}

O processo compreendeu o conteúdo programático definido no projeto pedagógico do curso e abordava as dimensões de avaliação de Bloom (1983): avaliação diagnóstica no período inicial, seguido de avaliação formativa (prova individual, entregas e trabalhos em equipe), e a avaliação somativa na fase final.

A jornada da construção de startups foi composta por sete etapas: 1) Ideia/problema; 2) Validação do problema; 3) Brainstorming; 4) Solução; 5) Validação da Solução; 6) Conquista de clientes e 7) Apresentação Final (Figura 1).

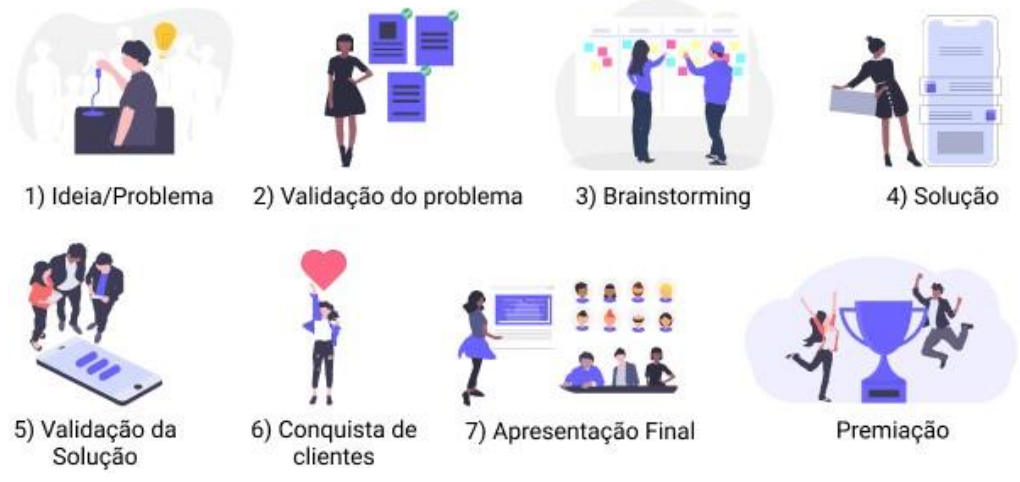

Figura 1. Jornada da Mostra de Ideias.

$\mathrm{Na}$ etapa 1 os acadêmicos levantavam problemas e apresentavam em sala suas ideias iniciais de solução; na etapa 2 faziam uma imersão in loco para validar a relevância do problema através de entrevistas e pesquisas; na etapa 3 discutiam de forma criativa as possíveis soluções; na etapa 4 construíam um protótipo da solução; na etapa 5 validavam a solução com pessoas interessadas; na etapa 6 criavam campanhas para conquistar potenciais clientes, e por fim, na fase 7 , munidos dos dados produzidos ao longo do 
semestre, criavam uma apresentação de impacto para apresentar suas soluções e argumentar com uma banca de especialistas em um evento aberto ao público. Durante essas etapas foram ministradas seis (06) oficinas práticas (Tabela 1) com profissionais externos convidados e, para cada oficina, as equipes cumpriam metas extraclasse que atualizavam sua pontuação em um ranking. Em todas as etapas utilizavam ferramentas online e gratuitas (por exemplo: Adobe XD, Figma, Wix/Wordpress, Canva. etc).

Tabela 1. Fases e Oficinas ministradas

\begin{tabular}{|l|l|}
\hline \multicolumn{1}{|c|}{ Fase } & \multicolumn{1}{c|}{ Oficina } \\
\hline 1) Ideia/Problema & - \\
\hline 2) Validação do problema & Oficina 1: Modelagem \\
\hline 3) Brainstorming & Oficina 2: Planejamento Estratégico \\
\hline 4) Solução & Oficina 3: Prototipação \\
\hline 5) Validação da solução & Oficina 4: Viabilidade Financeira \\
\hline 6) Conquista de clientes & Oficina 5: Marketing Digital \\
\hline 7) Apresentação final & Oficina 6: Apresentação de Impacto \\
\hline
\end{tabular}

\section{Relato de experiência}

A Mostra de Ideias consolidou-se como uma verdadeira jornada de conhecimento, trazendo experiência tanto para os alunos, que protagonizaram seu aprendizado intervindo na realidade, quanto para o professor, que acompanhou os acadêmicos na imersão in loco dos problemas investigados.

Toda esta jornada foi divulgada através das redes sociais da Mostra de Ideias. As fotos, vídeos, depoimentos e o próprio ranking foram compartilhados de modo que, além de divulgar os trabalhos dos acadêmicos, ainda serviram como uma ferramenta de motivação e engajamento. Um dos sinais de engajamento foi visto, por exemplo, quando as equipes, por vezes, permaneceram trabalhando na sala muito além do horário das aulas. Esse empenho e o interesse dos alunos nos diferentes momentos (Figura 2) foram características marcantes e serviram como motivação também no trabalho docente.

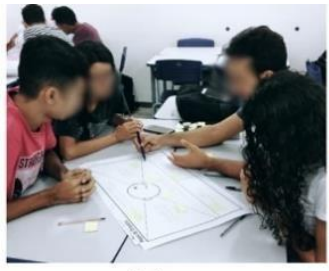

(a)

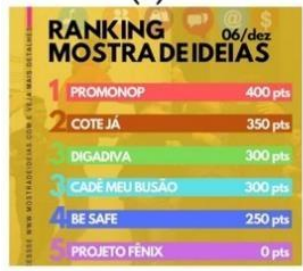

(d)

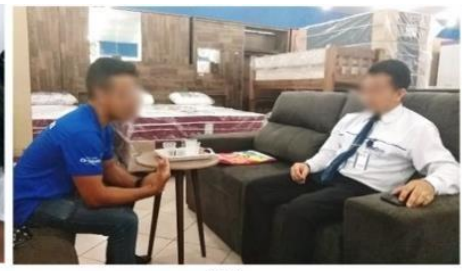

(b)

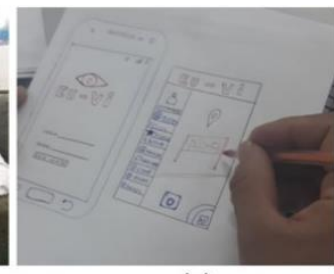

(c)

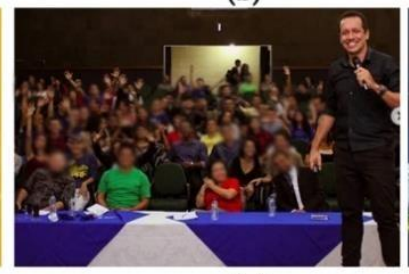

(e)

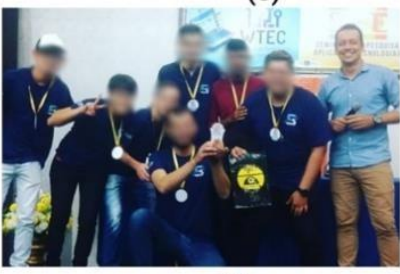

(f)

Figura 2. Diferentes momentos: (a) Modelagem; (b) Validação do problema; (c) Prototipação; (d) Ranking; (e) Apresentação final e (f) Premiação.

Uma percepção interessante foi que muitos alunos criaram fortes vínculos com seu trabalho e com suas equipes (veja exemplos de equipes na Figura 3), de modo que se 
sentiram orgulhosos por suas criações. Era comum ouvi-los fazendo retrospectivas de suas histórias, relembrando seus erros e acertos durante o semestre, reforçando que, de fato, passavam por uma experiência. Outro ponto em destaque foi o fato de que uma das startups - BlueDoor - que desenvolveu uma solução para aluguel de espaços ociosos, continuou seu desenvolvimento fora da Universidade, chegando a despertar interesse de investimento externo. Já outras chegaram a ser selecionadas em programas de préaceleração da região.

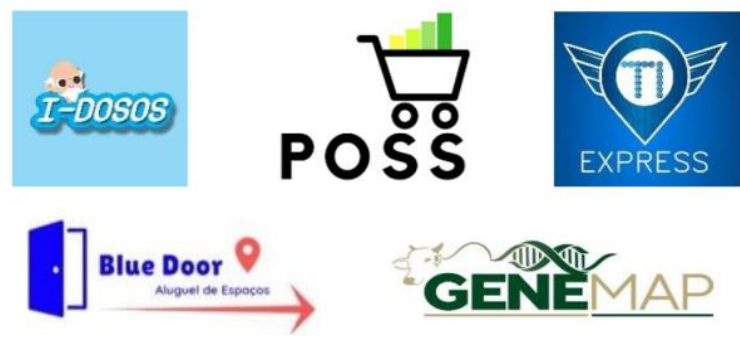

Figura 3. Exemplos de startups criadas durante a Mostra de Ideias.

Para captar a percepção dos alunos sobre a eficácia da metodologia, foi realizada uma pesquisa qualitativa e quantitativa para as quatro últimas turmas de acadêmicos do curso de Sistemas de Informação (2018-1 a 2019-2). A coleta de dados ocorreu através de questionários, entrevistas e observações in loco. O questionário foi produzido envolvendo os aspectos da Motivação, Experiência e Conhecimento, adaptado de Savi (2011) e atingiu 101 participantes. Sua aplicação foi realizada ao final de cada semestre e os alunos responderam de modo anônimo, para alcançar a maior fidelidade possível.

O resultado demonstrou que $85 \%$ classificou como "muito bom/bom", 13\% como "Regular" e 2\% como "Ruim". Ao serem solicitados para definir a metodologia apresentada em uma única palavra, os alunos utilizaram quarenta e sete (47) termos diferentes. As dez mais utilizadas foram: "Inovadora" com 10 respostas, "Interessante" com 9; "Boa" com 8; "Diferente", "Excelente", "Ótima" e "Surpreendente" com 4 respostas, e "Desafiadora", "Show" e "Incrível" com 3.

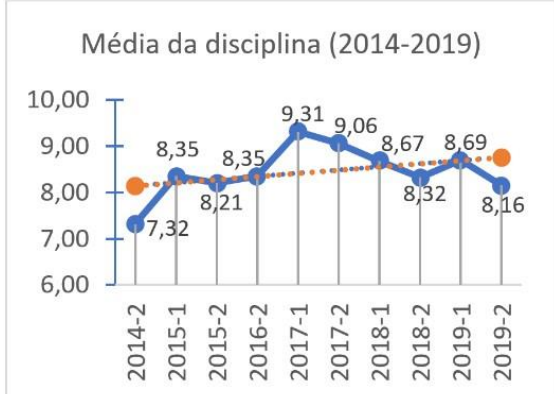

(a)

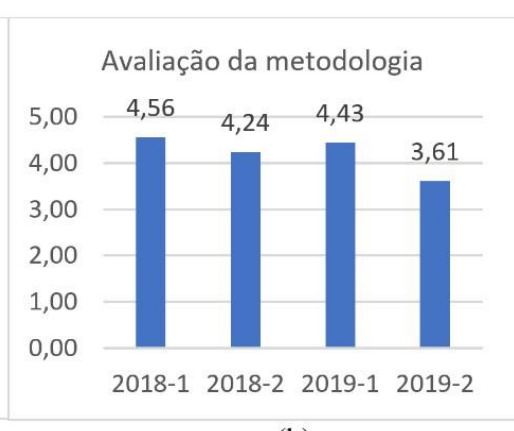

(b)

Figura 3. (a) Média da disciplina por semestre; (b) Avaliação da metodologia

Quanto à análise do histórico das médias obtidas pelos alunos, a aplicação da metodologia (período 2017-1 até 2019-2) contribuiu para sua evolução, conforme percebido na Figura 3 (a). Em termos quantitativos, os alunos avaliaram com uma nota entre zero e cinco: em 2018-1 a média obtida foi 4,56; em 2018-2 foi 4,24; em 2019-1 foi 4,43 e em 2019-2 foi 3,61, conforme visto na Figura 3 (b). Presume-se que em 2018-1 a avaliação foi melhor devido ao alto nível de engajamento da turma. A mesma percepção ocorreu com a turma de 2019-1. Acredita-se que o "engajamento" é primordial para esta metodologia. 


\section{Considerações finais}

Naturalmente, a metodologia evoluiu ao longo do tempo. Inicialmente, contava apenas com um docente, e evoluiu para uma rede de outros profissionais atuando como mentores. Também foi necessária a criação de uma equipe de monitores para auxiliar na gestão.

A realização da metodologia ao longo de seis (06) edições gerou mais de trinta (30) ideias modeladas e aproximadamente duas mil (2000) pesquisas de validação realizadas pelos alunos. Com os resultados deste trabalho, conclui-se que a Mostra de Ideias gerou resultados positivos, tanto quantitativos como qualitativos.

Para trabalhos futuros, pretende-se investigar mais profundamente o perfil dos ingressos e o fato de que as turmas do meio de ano apresentam menor engajamento e médias mais baixas na disciplina e avaliam a metodologia com notas menores, quando comparadas com as turmas de início do mesmo ano. Mais detalhes sobre as edições, como fotos, vídeos e outras informações podem ser encontrados na rede social (www.instagram.com/mostradeideias) e no site oficial (www.mostradeideias.com).

\section{Referências}

Barrows, H. S. Problem-based learning in medicine and beyond: a brief overview. In: Wilkerson L.; Gilselaers H. (Eds.). Bringing problem-based learning to higher education: theory and practice. San Franscisco, CA: Jossey-Bass Inc., 1996. p. 3-11.

Bloom, B. S.; Hastings J. T.; Madaus, G. F. Manual de Avaliação Formativa e Somativa do Aprendizado Escolar. São Paulo: Livraria Pioneira Editora, 1983.

Gonçalves, B. et al. Elementos de Gamificação Aplicados no Ensino-Aprendizagem de Programação Web. In: Workshop Sobre Educação em Computação (WEI), 27. 2019, Belém. Anais do XXVII Workshop sobre Educação em Computação. Porto Alegre: Sociedade Brasileira de Computação, julho 2019, p. 1-10. ISSN 2595-6175.

Guedes, K. de L. et al. A Avaliação de Estudantes e Professores de Administração sobre a Experiência com a Aprendizagem Baseada em Problemas. Administração: Ensino e Pesquisa, vol. 16, núm. 1, 2015, pp. 71-100.

Lirbório, L. F. et al. O Ensino do Empreendedorismo no Brasil: Uma Análise da Metodologia do Células Empreendedoras. 2019. 12 f. - CONEDU - Congresso Nacional de Educação, 2019.

Santos, D. M. B. et al. Aplicação do método de aprendizagem baseada em problemas no curso de Engenharia de Computação da Universidade Estadual de Feira de Santana. 2007. Departamento de Ciências Exatas, Universidade Estadual de Feira de Santana.

Savi, R. et al. Proposta de um Modelo de Avaliação de Jogos Educacionais. 2010. 12 f. Curso de Novas Tecnologias na Educação, Universidade de Santa Cantarina, Santa Catarina, 2010.

Silva, J. K. F.; Gontijo, F. B. Aplicação do Método Aprendizagem Baseada em Problemas (ABP) ao Curso de Engenharia Civil do UNIPAM. 2015. 20 f. Dissertação (Mestrado) - Centro Universitário de Patos de Minas, Patos de Minas, 2015.

Techstars. Startup Weekend - Learn, Network, Startup, 2020. Página inicial. Disponível em: $<$ https://startupweekend.org/>. Acesso em: 25 de abr. de 2020.

Vianna, Y., Vianna, M., Medina, B., Tanaka, S. (2013). “Gamification, Inc.: Como Reinventar Empresas a partir de Jogos". Rio de Janeiro: MJV. 